\title{
Göçmenlerde Aşılama
}

\author{
Immunization in Refugee Children
}

Elif Nur Özmert

\author{
Hacettepe Üniversitesi Tıp Fakültesi, Çocuk Sağlığı ve Hastalıkları Anabilim Dalı, \\ Ankara, Türkiye
}

\begin{abstract}
Özet: Tüm dünyada çocuk sağlığı sorunları konusunda iyileşmeler olurken ne yazık ki son yıllarda gittikçe artan zorla yerinden edilme nedeniyle çocuklar mortalite ve morbiditede artış riski ile karşı karşıya kalmaktadır. UNHCR 2018 yılı verilerine göre 70.8 milyon kişi zorla yerlerinden edilmiştir. Bunun da 25.9 milyonu mülteci durumundadır. Enfeksiyon hastalıkları çoklu nedenler ile ortaya çıkan morbidite ve mortaliteler arasındadır. Yaşanılan ve gelinen ülkedeki hastalık epidemiyolojisi, alt yapı imkanları, temiz su ve sanitasyona erişim, kalabalık yaşam, eşlik edebilecek beslenme bozukluğu, sağlık sistemine erişim, insani yardımların engellenmesi ve aşılama enfeksiyon hastalıklarının morbidite ve mortalitesini belirleyen faktörler olarak sıralanabilir. Aşı ile önlenebilen hastalıklar ve salgınların önlenmesinde aşılama hizmetleri özellikle önemli yer tutar. Suriye'deki insani krizin ardından Türkiye'de resmi rakamlara göre 3.7 milyon Suriyeli geçici koruma altında (GKA) misafir bulunmaktadır ve bunun \%15'i beş yaşın altındadır. Önceleri 26 geçici barınma merkezi (GBM) ve toplumda yaşayan GKA Suriyelilerin bugün yanlızca yaklaşık 63.000'i, 5 ildeki 7 GBM'de kalmaktadır. GKA altındaki Suriyelilere sınır kapsından geçişlerde çocuklara OPA, KKK, DTaB-IPA-Hib, DTaB-IPA ve 15-49 yaş arası kadınlara da difteri-tetanoz aşısı yapılmaktadır. Sınırda kayıt altına alınan GKA Suriyelilere bunun ardından yaşına uygun olarak aşıları ulusal bağışıklama programı kapsamında, Göçmen Sağlığı Merkezleri, Göçmen Sağlığı Birimleri veya Aile Sağlğı Merkezleri tarafindan ücretsiz olarak yapılmaktdır. GKA misafirler için yüksek aşı oranlarına ulaşmayı sağlayacak GBP stratejileri 2017 yılında şöyle belirlenmiştir: Sunulan rutin aşılama hizmetlerinin geliştirilmesi ve aşılama oranlarının her bölgede \%90'nın üzerine çıkarılarak devam ettirilmesi; Rutin aşılama çalışmalarına ek olarak destek aşılama ve eksik aşı tamamlama çalışmaları yapılması; Gerek görülen yerlerde saha çalışmaları (gerekirse kapı-kapı dolaşılarak) ile aşı günleri düzenlenmesi. Göçmen, ve sığınmacılara sunulan aşılama hizmetlerini devlet ve göçmen-sığınmacı düzeyinde etkileyen pek çok faktör vardır. Bu fakörlerin belirlenmesi aşılanma oranlarının artırılması için uygun stratejilerin geliştirilmesinde önemlidir.
\end{abstract}

Anahtar Kelimeler: Aşılama, göçmen, Suriye, geçici koruma

\begin{abstract}
Despite improvement in child health issues, forcibly displaced children are encountering increased risk of morbidity and mortality. According to UNHCR 2018 data 70,8 million people are forcibly displaced and 25,9 million are refugee. Infectious disease are multifactorial. Disease epidemiology of home country and host country, infrastructure, access to clean water and sanitation, crowding, associated malnutrition, access to health care services, obstruction of humanitarian aid and immunization are among the important factors determining morbidity and mortality of infectious diseases. Immunization is vital for vaccine preventable diseases. After the Syrian crisis, according to official numbers there are 3,7 million Syrian under temporary protection status in Turkey whom $15 \%$ are under 5 years of age. Currently only 63.000 are living in temporary protection areas. While passing the border children are given OPV, MMR, DTaP-IPV-Hib, DTaP-IPV and 15-49 years old women diphtheria-tetanus vaccines. After being registered Syrian children under temporary protection are vaccinated according to national immunization program free of charge at Migrant Health Centers or Family Health Centers. Strategies to increase immunization coverage in Syrian children under temporary protection have been determined as follows in 2017: improvement in routine national immunation program for Syrian children and targeting $90 \%$ coverage in every region; supplementary immunization activities and catch-up campaigns; MOP-UP and mobile immunization teams. There are several factors effecting the immunization coverage at state and refugee level. Identification of the factors will contribute to develop best strategies to increase immunization coverage in refugee children.
\end{abstract}

Keywords: İmmunizaton, refugee, Syria, temporary protection

ORCID ID of the author: E.N.Ö. 0000-0002-4911-9200 e-mail: elifnurselozmert@gmail.com 


\section{Giriş}

$\mathrm{Bu}$ yazının başlığı "göçmen" ifadesini içermekle birlikte aslında konuyu daha fazla ayrıntılandırmadan önce günümüzde siklıkla karşılaştığımız bazı tanımları bir kez daha yapmak uygun olacaktır.

Göçmen terimi genellikle, bireyin göç etme kararını, zorlayıcı dış faktörlerin müdahalesi olmaksızın kendi özgür iradesiyle ve 'kişisel uygunluk' sebepleriyle aldığı tüm durumları kapsar. Dolayısıyla bu ifade, maddi ve sosyal koşullarını iyileştirmek ve kendileri ve ailelerine ilişkin beklentilerini geliştirmek amacıyla başka bir ülkeye veya bölgeye hareket eden kișiler ve aile fertleri için geçerli kabul edilmiştir. (1) $\mathrm{Bu}$ tanım kapsamında göçmenlere önerilen aşı uygulamaları kişinin yaşı, göç edilen ülkedeki hastalık epidemiyolojisi ve aşı programı ve ayrıldıkları ülkenin hastalık epidemiyolojisi ve aşı programina göre farkl1liklar gösterebilmektedir. Bu yazı kapsamında bu konuya ayrıntılı olarak değinilmeyecektir.

Mülteci ise "Irk1, dini, tabiiyeti, belirli bir sosyal gruba mensubiyeti ve siyasi görüşleri yüzünden haklı bir zulüm korkusu nedeniyle vatandaşı olduğu ülkenin dışında bulunan ve söz konusu korku yüzünden, ilgili ülkenin korumasından yararlanmak istemeyen kişi" olarak tanımlanır. (1)

Sığınmacı, iltica başvurusunda bulunmuş kişidir. (1)

Geçici koruma statüsü ise, çatışma veya yaygın şiddet ortamlarından kitlesel olarak kaçıp gelen kişilere öncesinde bireysel statü belirleme işlemine tabi tutulmaksızın Devlet tarafından geçici koruma sağlama konusunda geliştirilen düzenlemedir. Türkiye'de Suriyeliler bu statü altında yaşamaktadır. (1) $\mathrm{Bu}$ yazıda ayrıntılı olarak ülkemizde geçici koruma altında bulunan misafirlerimize yapılan aşı uygulamaları anlatılacaktır.

UNHCR (Birleşmiş Milletler Mülteciler Yüksek Komiserliği) 2018 yılı verilerine göre dünyada 70.8 milyon kişi doğal afetler dışında, zorla yerinden edilmiştir. Bu sayının 13.6 milyonu 2018 yılında yerinden edilmiştir ve her gün 37 bin kişi zorla göç etmektedir. Zorla göç edenlerin 25.9 milyonu mülteci durumunda, 3.5 milyonu sığınmacıdır. Zorla yerinden göç etmiş 41.3 milyon kişi ise ülkelerinin içinde göç etmiştir. (2)

Çatışma ve göçün sağlığa etkileri pek çok faktörlüdür. Bu durumdan da en çok olumsuz etkilenenler, hassas gruplar, yani, yaşli, engelli, kadın ve çocuklardır. (3)

Çatışma, göç ve sağlık ilişkisinde, göçten önceki durum, göç süreci ve göç edilen ülkedeki şartlar sağlık sonuçlarını belirler. Göç öncesi yaşanan travma, şiddet, sağlık davranışı ve inançları, hastalık epidemiyolojisi ve alınan sağlık hizmeti, göç sürecinin süresi, yaşanan travma, bireysel veya toplu göç olması, bu süreçte alınan sağlık hizmetleri ve yaşam koşulları, göç edilen ülkenin hastalık epidemiyolojisi, sağlanan haklar, sağlanan yaşam koşulları, resmi, statü, ayrımc1lık, dil-kültür farklılıkları, ailenin bütünlüğü gibi pek çok faktör göç eden kişinin sağl1k durumunun belirleyicisi olacaktır. (3)

Yukarıda siralanan tüm etkenlerde göz önünde bulundurularak çatışma ve göçün çocuklar üzerindeki direk ve dolaylı sağlık etkileri şöyle sıralanabilir; (4)

•Ölüm, yaralanma

-Çocuk asker

•Cinsel sömürü

•Yoksulluk

•Çocuk işçiliği

-Artan enfeksiyon hastalıkları

•Beslenme bozukluğu

-Yenidoğan sağl1k sorunları ve üreme sağlığı sorunları

-Bulaşıc1 olmayan hastalıkların tanı ve tedavisinde yetersizlikler

•Akıl-ruh sağlığı sorunları

$\mathrm{Bu}$ sorunlar arasında aşı ile önlenebilir enfeksiyon hastalıklarının artışı da pek çok faktör ile ilişkilidir: 
-Hastalıkların epidemiyolojisi

-Alt yapının zarar görmesi/yetersizliği

-Temiz suya erişimin engellenmesi yetersizliği

-Sanitasyon ve hijyen olanaklarının kısıtlılığı

-Kalabalık yaşam

-Sağlık sisteminin bozulmas1/yetersizliği

-Aşıya erişimin kısıtlanması/yetersizliği

-İnsani yardımların engellenmesi

-İlaca erişimin engellemesi

UNICEF verileri incelendiğinde, Suriye'de savaş sonrası bir yaş altı çocuklarda ishale bağlı ölümlerin 2 kat arttığ görülmektedir. Bir başka çalışmada ise terörizm ve ilişkili şiddete bağlı ölümlerin her \%1'lik artışının ishalli hastalıklar, şistozomiasiz ve nematod enfeksiyonlarına bağlı DALY'i (Yeti Yitimine Ayarlanmış Yaşam Yılı -Disability Adjusted Life Years) 0-4 yaş çocuklarında sonraki 2 yıl için \%0.16 artırdığ 1 saptanmıştır. (5)

DSÖ 2019 verilerine göre dünyada 10 ülkede DBT3 veya tek doz kızamık aşı uygulaması $\% 50$ 'nin altındadır. Bu 10 ülkeden 8 tanesi çatışma altındaki ülkelerdir.

Aşılanma oranları incelendiğinde Suriye'de savaştan sonra, DBT3 aşılanma oranının $\% 95$ 'lerden, kızamık aşılanma oranının ise \%80'lerden, \%50'ler civarına düştügü görülmektedir. Polio vakalarını \%67'sinin, kızamık vakalarının ise \%39'unun 2010-2015 yılları arasında çatışma içindeki 16 ülkede görüldüğü bildirilmiştir.(6)

Türkiye'deki resmi verilere göre 3.5 milyondan fazla Suriyeli geçici koruma altında (GKA) misafir bulunmaktadır. Bunların \%2'den azı 5 ildeki (Adana, Kilis, Hatay, KahramanMaraş, Osmaniye) 7 barınma merkezinde yaşamaktadır. Bildirilen nüfusun \%13,3'ü 0-4 yaş arasındadır.(7)

Türkiye'de GKA misafirlere temel olarak 4 farklı aşılama stratejisi uygulanmaktadır.
-Sınır geçişlerinde

-Rutin ulusal aşılama

-Salgın durumlarında ek aşılama

-Aşı tamamlama ve hızlandırma

Bunun yanı sıra düzensiz göçmenlere hizmet veren "Geri Gönderme Merkezlerinde" çalışan veya düzensiz göçmenlerle doğrudan temas halinde risk altında bulunan tüm personele de influenza, en az biri yetişkin tip boğmaca aşısı içeren tetanoz-difteri aşısı, hepatit $\mathrm{B}, \mathrm{KKK}$, hepatit $\mathrm{A}$, suçiçeği, oral polio, meningokok aşılarının uygulanması önerilmiştir. (8)

Sınır geçişlerinde uygulanan aşılar şöyledir;

-OPA (0-15 yaş arası),

•KKK (9 ay-15 yaş arası)

•DTaB-İPA-Hib (7 yaş altı),

•DTaB-İPA (7-12 yaş arası),

-15 - 49 kadınlara difteri-tetanoz

Türkiye'de GKA misafirlerin sağlık hizmetlerine eşit ücretsiz erişim hakkı vardır. $\mathrm{Bu}$ kapsamda daha etkili bir hizmet sunabilmek için Göçmen Sağlığı Merkezleri (GSM) de oluşturulmuştur. Bu Merkezler birinci ve ikinci basamak sağlık hizmetleri sunabilmektedir. Türkiye'de 173 (688 birim) vardır, 2019 sonunda bu sayının 182 (805 birim) olmas1 hedeflenmektedir. $\mathrm{Bu}$ merkezlere ilişkin Halk Sağlığı Müdürlüğünün bildirimi şöyledir;(9)

“GSM'ler, ülkemizdeki aile hekimliği uygulamasına benzer şekilde, ortalama her 4.000 kişiye hizmet verecek bir hekim ile bir yardımcı sağlı personelinden oluşan göçmen sağlığı birimlerini (GSB) ihtiva etmekte, aile hekimliği için tanımlanan fiziki ve teknik standartları taşımaktadır.

Nüfusu nispeten yüksek olup tam teşekküllü bir kamu hastanesine uzak olan geçici barınma merkezleri ile Suriyeli sayısının 20 binin üzerinde olduğu yerleşim yerlerinde Güçlendirilmiş GSM teşekkül ettirilmektedir. 
Güçlendirilmiş GSM'de; birinci basamak sağlık hizmetlerine ilave olarak dâhiliye, çocuk, kadın-doğum, ağız-diş sağlığı ve psikososyal destek hizmetleri sunulmakta; hizmetler, görüntüleme üniteleri ve basit hizmet laboratuvarları ile desteklenmektedir. Böylelikle, hizmetlere erișimin artırılması, hastanelerin yükünün azaltılması amaçlanmaktadır.

GSM'lerde, Suriyeli sağlık personeline ilave olarak, iki dil bilen (Arapça-Türkçe) hasta yönlendirme elemanları ile destek hizmetleri personeli de görev yapmaktadır.

$\mathrm{Bu}$ merkezler, "Toplum Sağlığı Merkezi ve Bağlı Birimleri Yönetmeliği” doğrultusunda "TSM Bağlı Birimi” olarak teşekkül ettirilmektedir.

GSM'lerin yaygınlaştırılması ve işletilmesi ile çalışan personelin istihdamına dair giderler SIHHAT Projesi kapsamında karşılanmaktadır.

Geçici koruma altındaki Suriyelilere sunulan birinci basamak sağlik hizmet verileri "Muayene Bilgi Yönetim Sistemi" kullanılarak kayıt altına alınmaktadır."

GSM'de ulusal aşı programı tüm çocuklara verilmektedir. Türkiye'de, GKA misafirlere 2018 y1lı itibariyle toplam 4.520.095 doz aş1 uygulaması yapılmıştır. $\mathrm{Bu}$ sayının içine salginlar nedeniyle yapilan OPV ve KKK aşıları dahil değildir. (10) Türkiye Nüfus Sağlık Araştırmaları 2018 Suriye raporuna göre (11), 12-23 aylık bebeklerde aşı kartı ve anne beyanına göre yaşına uygun aş11 olanalar \%60'dır bu rakam Türkiye raporunda (12) \% 67'dir.

Daha öncede vurgulandığ 1 gibi enfeksiyon hastalıklarını ve bununla ilișkili mültecilere yapılacak aşı uygulamalarını hastalık epidemiyolojjsi ve göçün şekli de belirlemektedir. Bununla birlikte mülteci ve göçmenlere yönelik aşı uygulamalarının değerlendirildiği bir çalışmada, Avrupa Birliği ülkelerinde, 26 ülkede ulusal aşı programının, 2 ülkede ayrı aşı programının uygulandığı, 26 ülkede aşıların ücretsiz, 2 ülkede ergenlere için bazı aşıların ücretli olduğu bildirilmektedir. Așlar 5 ülkede giriște, 21 ülkede bekleme alanında, 6 ülkede GSM yapılmaktadır. Avrupa Birliğindeki 26 ülkede mülteciler için toplumda ayrıca aşılanma devam etmektedir. (13)

GKA misafirlere verilmiş olan bir diğer aş1 hizmetini salgınlar sırasındaki aşılmalar oluşturmaktadır. Suriye'de 2011 yllında karıșıklıkların ve göçün başlaması, savaş ve göçle ilgili tüm risklerin beraberinde, başta sağlık sistemindeki bozulmalar ve aşılanma oranlarının da düşmesi ile 2013 yılında 35 poliomiyelit vakası saptanmıștır. Bunun üzerine Türkiye'de 2013-2015 yılları arasında 9 turda 18 ilde (Şanlıurfa, Adana, Adıyaman, Osmaniye, Malatya, Kahramanmaraş, Hakkari, Siirt, Van, Batman, Diyarbakır, Mersin, Şırnak, Gaziantep, Hatay, Kilis, Mardin, İstanbul-6 ilçe) yerli ve yabancılara toplam 5.288.639 doz OPV aşıs1 yapılmıştır.(10)

Bunun dışında, 2013-2015 yılları arasında kızamık kontrol çalışmaları kapsamında da hassas ve aşısız olan Suriyeli çocuklara 2.381.626 doz aş1 yapılmıştır.(10)

GKA misafirlerin aşılanmasına yönelik son bahsedeceğimiz aşı çalışması da, aşı tamamlama ve hızlandırma çalışmasıdır. Ağırlıklı olarak Adana, Adıyaman, Ankara, Bursa, Diyarbakır, Batman, Gaziantep, Hatay, İstanbul, İzmir, Kahramanmaraş, Kayseri, Kilis, Kocaeli, Konya, Malatya, Mardin, Mersin, Osmaniye, Şanlıurfa olmak üzere tüm Türkiye'de 0-59 ay yaş grubundaki göçmen çocuklar bulundukları yerde ziyaret edilerek, kayıtsız olanlar kayıt altına alınmış, aşısı olmayan $\neg$ lara ya da aşısı eksik bulunanlara ilk temasta KKK, Beşli karma ve Hep B Aşısı uygulanmıștır. Çalıșmada, 5000 sağlık çalışanı, 495 istasyon, 192 gezici ekip yer almıştır. $\mathrm{Bu}$ çalışmada yaklaşık 370 bin çocuğa ulaş1lmıştır, 358.000 çocuğa KKK, 120.000 çocuğa Polio, DaBT-IPV-Hib, Hep B aşı1sı yapılmıştır. (10)

DSÖ Avrupa Bölgesi Raporuna göre mülteci ve göçmenlere verilen sağllk hizmetleri ve aş1 uygulamalarında ülkeler arasında farklılıklar 
vardır. Ulusal programlarda göçmen ve sığınmacılara özgü öneriler nadiren yer almakta ve ancak $1 / 3$ ülkeden azında özel önerilere yer verilmektedir. Bunun yanı sıra düzensiz/kayıtsız göçmenler çok az ülkede sağlık hizmetlerine ulaşabilmektedir. Çoğu ülkede aşılama ulusal halk sağlığı hizmeti olarak verilse de, uluslararası kuruluşlar ve STK da katkı sağlamaktadır. (14)

\section{KAYNAKLAR}

1. No 31 Göç Terimleri Sözlügüu. Perruchoud R, Redpath - Cross J (eds). Uluslararası Göç Örgütü. 2. Bask1 2013, Ankara

2. UNHCR.Figures at

Glance.https://www.unhcr.org/ph/figures-at-aglance (son erişim 22.01.2020)

3. IOM,WHO,UNHR. International migration, health and human rights, 2013. Geneva IOM 2013.

4. Shenoda S, Kadir A, Pitterman S, Goldhagen J and Section On International Child Health The Effects of Armed Conflict on Children Pediatrics 2018; 42 (6) e20182585.

5. Kerridge BT, Khan MR, Rehm J, Sapkota A. Conflict and diarrheal and related diseases: A global analysis J Epidemiol Glob Health. 2013; 3: 269-77.

6. Grundy J, Biggs BA. The Impact of Conflict on Immunisation Coverage in 16 Countries. Int $J$ Health Policy Manag. 2019;8:211-21

7. TC İçişleri Bakanlığı Göç İdaresi Genel Müdürlüğü $\quad$ istatistikleri https://www.goc.gov.tr/gecici-koruma5638 (son erişim 22.01.2020)

8. TC Sağlik Bakanlığı Halk Sağlığ Müdürlüğü Așı Portalı. Mesleğe Bağlı Riskler Nedeniyle Aşlama https://asi.saglik.gov.tr/asikimlere-yapilir/liste/32-mesleğe-bağl1-risklernedeniyle-aşlama.html (son erişim 22.01.2020)

9. TC Sağlık Bakanlığı Halk Sağlığı Genel Müdürlüğü. Göç Sağlığı Dairesi Başkanlığı

https://hsgm.saglik.gov.tr/tr/göçmen-sağlı̆̆1merkezleri.html (son erișim 22.01.2020)

10. Önder N. Türkiye'de Geçici Koruma Altındaki Suriyelilere Yönelik Sağlık Politikalarının Analizi. Göç Araştırmaları Dergisi 2019;5: 110-165.

11. Hacettepe Üniversitesi Nüfus Etütleri Enstitüsü. (2019). 2018 Türkiye Nüfus ve Sağlık Araştırması Suriyeli Göçmen Örneklemi. Hacettepe Üniversitesi Nüfus Etütleri Enstitüsü, T.C. Cumhurbaşkanlığı Strateji ve Bütçe Başkanlığı ve TÜBITTAK, Ankara, Türkiye.

12. Hacettepe Üniversitesi Nüfus Etütleri Enstitüsü. (2019). 2018 Türkiye Nüfus ve Sağlık Araştırması. Hacettepe Üniversitesi Nüfus Etütleri Enstitüsü, T.C. Cumhurbaşkanlığı Strateji ve Bütçe Başkanlığı ve TÜBİTAK, Ankara, Türkiye.

13. Giambia C, Del Mansoa M, Marchettia G, Olssonc $\mathrm{K}$, Alic KA, Declicha $\mathrm{S}$, the Venice survey working group Immunisation of migrants in EU/EEA countries: Policies and practices Vaccine. 2019;37:5439-51.

14. De Vito E, Parente P, de Waure C, Poscia A, Ricciardi W. A review of evidence on equitable delivery, access and utilization of immunization services for migrants and refugees in the WHO European Region. Copenhagen: WHO Regional Office for Europe; 2017 (Health Evidence Network (HEN) synthesis report 53). 